\title{
The Effect of Dislocation Substructure and Decomposition on the Course of Diffusionless Transformations
}

D. Treppmann and E. Hornbogen

Ruhr-Universität Bochum, Institut für Werkstoffe, 44780 Bochum, Germany

\begin{abstract}
The mechanical properties (yield strength, hardness, transformation stresses) and the transformation temperatures of SMA can be affected by the combination of different solid-state reactions. In this context the combination of local change in chemical composition by precipitation processes and the rearrangement of defects by recovery and recrystallization are of special interest. The influence of different heat treatments on Ni-rich $\beta$-NiTi-alloys was investigated by polarization light microscopy, TEM, DSC-measurements and microhardness tests above $\mathrm{M}_{\mathrm{d}}$. Of particular interest were the occurance and interactions due to the different nature of martensitic (M-) phase and R-phase transformation.
\end{abstract}

\section{Introduction}

For the optimization of Shape Memory Alloys (SMA) two different properties have to be connected: 1. The optimization of functional qualities (transformation temperatures, transformation stresses) which are given by the chemical composition and the microstructure. These qualities should allow a complete reversiblity of transformation. 2. The optimization of structural properties which can be described by the term "strength" (e. g. Y.S., hardness) to enable power operations for couplings and grippers. These properties can be achieved by high dislocation densitiy and/or fine dispersion of particles. In order to meet both requirements concerted thermomechanical treatments are utilized to release "combined reactions" in the shape memory materials. The term "combined reactions" is used for solid-state reactions which are composed of more than one of the following reactions /1/: a) Transformation (phase transformation $\alpha \leftrightarrow \beta$ ). b) Decomposition (precipitation of Ni-rich particles). c) Healing out of defects (recovery and recrystallization). Two or more of these reactions enable thermomechanically treated Nirich NiTi-alloys to approach the equilibrium.

\section{Experimental Methods}

A binary NiTi alloy with a nominal composition of 51.5 at $\% \mathrm{Ni}$ was investigated. The cast ingots were compacted by hot swaging (deformation temperature $\approx 920^{\circ} \mathrm{C}$ ) and subsequently cold swaged using a cold deformation strain of $30 \%$ (final diameter: $10 \mathrm{~mm}$ ). A heat treatment at $350{ }^{\circ} \mathrm{C}, 450{ }^{\circ} \mathrm{C}, 550^{\circ} \mathrm{C}$ and $600{ }^{\circ} \mathrm{C}$ for 30 minutes in air was carried out immediately after cold work.

The microstructure was studied by transmission electron microscopy and by polarized light microscopy (LM). TEM samples were prepared by electropolishing thin foils (Struers A8). To get an optimum polished surface quality for light microscopy, an electrolyte (Struers A2) was used after 
grinding. The electropolishing was followed by a colour process etching in Beraha I and $14 \mathrm{~g}$ potassium disulfite.

The transformation temperatures were determined by Differential Scanning Calorimetrie (DuPont DSC 2001). For mechanical characterization the Vickers hardness (D.P.H.) was measured. The hardness tests were carried out at $200{ }^{\circ} \mathrm{C}$ (in the stable austenitic phase) to avoid the influence of testing temperature on the compareability of microhardness results. A weight of 100 pond $(\approx 1 \mathrm{~N})$ was used. The heat transfer was realized by an inductive heated specimen holder.

\section{Results and Discussion}

\subsection{Microstructure}

All surfaces show a random distribution of inclusions. The composition seems to be $\mathrm{Ti}_{2} \mathrm{Ni}_{2} \mathrm{Ti}_{4} \mathrm{Ni}_{2} \mathrm{O}_{x}$ respectively and can be analysed by energy dispersive $x$-ray analysis as well as by electron diffraction pattern. Due to their higher microhardness an accumulation can lead to a fracture failure of the matrix during loading.

No significant difference in microstructure can be found between the cold worked initial state (IS) and the heat treated conditions up to $550{ }^{\circ} \mathrm{C}$ by light microscopy. All samples show austenitic grains including a deformation structure (Fig. 1). The average grain size is about $85 \mu \mathrm{m}$, determined at a magnification of $125: 1$. TEM is yielding more detailed informations about possible solid-state reactions. Between the cold worked initial state and the $350{ }^{\circ} \mathrm{C}$ heat treated condition no evident recovery can be found (Fig. 2). The microstructure seems to be similar to the deformations twins found by Moberly et al. 12/. In contrast to the initial state small precipitations (average diameter: 5 to $10 \mathrm{~nm}$ ) can be observed using darkfield images after $350^{\circ} \mathrm{C}$ heat treatment. An identification by diffraction pattern is not possible. According to results from Nishida et al. $/ 3 / \mathrm{Ni}$-rich precipitations $\left(\mathrm{Ni}_{4} \mathrm{Ti}_{3}, \mathrm{Ni}_{14} \mathrm{Ti}_{11}\right)$ are probable.

The $450{ }^{\circ} \mathrm{C}$ heat treatment causes a slight decrease in dislocation densitiy. Dark field images show a rise of the precipitation diameter $(40 \mathrm{~nm}$, see Fig. 3 $)$. Because of the defect control by dislocations the precipitation reactions follows the continuous mode.

Annealing at $550^{\circ} \mathrm{C}$ leads to a further drop of dislocation density. In contrast to the light microscopic observations small subboundary structures (average diameter: 0,2 to $0,45 \mu \mathrm{m}$ ) can be found by TEM (Fig. 4). No more precipitations can be observed after this thermal treatment. The phenomenon does not correspond to the observations made after comparable heat treatment in a sample immediately after hot swaging. The hot deformed microstructure shows lower dislocation density and plate-like precipitations of $200 \mathrm{~nm}$ length (Fig. 5). It is well known that dislocation density is able to affect the beginning of precipitation processes as well as the incoherency of precipitations because of the reduction of required nucleation energy $/ 4 \%$ On the other hand the dislocation density is also affecting the dissolution of particles: Diffusion along "dislocation pipes" is easier so that specimens with higher cold working rate can reach the homogenity range earlier.

The thermal treatment (of the former cold worked specimens) at $600{ }^{\circ} \mathrm{C}$ activates partial recrystallization processes. The grain size of the newly formed austenitic grains is between 5 and $12 \mu \mathrm{m}$ (Fig. 6 ). Subgrain formation can be observed in the neighbouring deformation structures by TEM. As expected, no precipitation processes can be observed (Fig. 7).

\subsection{Mechanical and Thermal Properies}

In an earlier work the influence of testing temperature on the validity of microhardness results has been investigated by microhardness measurements as a function of temperature $15 \%$. Valid microhardness results can be obtained in stable martensite $\left(T<M_{i}\right)$ and austenite $\left(T>M_{d}\right)$. In the intermediate temperature range it is impossible to obtain meaningful hardness values because of stress induced transformation. Due to this a temperature of $200{ }^{\circ} \mathrm{C}\left(\mathrm{T}>\mathrm{M}_{\mathrm{d}}\right)$ was chosen in order to avoid testing conditions in different phases and undesired thermal treatments. 
The increase of hardness after $350{ }^{\circ} \mathrm{C}$ heat treatment (in relation to the cold worked initial state IS) indicates that the small particles are coherent precipitations (Fig. 8).

Because of partial recovery and overaging of the $450^{\circ} \mathrm{C}$ heat treated specimens the microhardness again reaches the level of the initial state (Fig. 8). The rearrangement of dislocations may act as nucleation sites for incoherent particles by decreasing the requisite interface energy $/ 4 /$ It can be presumed that the precipitations loose their coherency with the matrix at a significant smaller particle size than precipitations in fully recrystallized matrix will do.

Further annealing $\left(550{ }^{\circ} \mathrm{C}, 600{ }^{\circ} \mathrm{C}\right)$ leads to increasing recrystallization and dissolution of precipitated particles. The microhardness reaches its minimum value (Fig. 8 ).

The samples show three different types of transformation courses during DSC measurements (Fig. 9). After heat treatment at $350^{\circ} \mathrm{C}$ and $550^{\circ} \mathrm{C}$ as well as in the cold worked initial state two peaks are found during cooling process and one peak during heating (Fig. 9a). A transformation course like shown in Fig. $9 \mathrm{~b}$ can be detected after annealing at $450{ }^{\circ} \mathrm{C}$. The maximum thermal treatment $\left(600{ }^{\circ} \mathrm{C}\right)$ yields a transformation behaviour with one peak during cooling and during heating (Fig. 9c). The transformation temperatures are shown in Table 1 . With exception of the $350{ }^{\circ} \mathrm{C}$ and the $450{ }^{\circ} \mathrm{C}$ heat treated samples, all specimens reach $A_{f}, A_{f}^{*}$ respectively at ambient temperatures. For simplification only the changes of R-phase start during cooling $\left(R_{c s}\right)$ and martensite start temperature $\left(M_{s}\right)$ will be discussed.

Martensite start temperature and hardness can be affected by the same solid-state reactions. Precipitation processes in $\mathrm{Ni}$-rich $\mathrm{NiTi}$-alloys influence the equilibrium temperature $\mathrm{T}_{0}$ (by shifting the chemical composition $\mathrm{c}_{\mathrm{Ni}}$ ) as well as the undercooling $\Delta \mathrm{T}_{\mathrm{M}}$ (by raising the real yield strength $\tau_{\mathrm{Y}}$ ). The effect of isothermal heat treatment is described in $/ 6 /$. Depending on the annealing temperature $T_{A}$, the effects of variables on the martensite start temperature can be described by:

$$
\left.\frac{d M_{s}}{d T_{A}}\right|_{t_{A}}= \pm \frac{\delta T_{0}}{\delta c_{N i}} \frac{\delta c_{N i}}{\delta T_{A}}-\frac{\delta \Delta T_{M}}{\delta \tau_{Y}} \frac{\delta \tau_{Y}}{\delta T_{A}}
$$

for constant annealing time $t_{\mathrm{A}}$ (isochronal reaction). This condition implies that the heat treatment only leads to full equilibrium for the higher annealing temperature. Recovery and recrystallization cause a decrease of the undercooling $\Delta \mathrm{T}_{\mathrm{M}}$ by decreasing the real yield strength $\tau_{\mathrm{Y}}$. If the probability of nucleation or the mobility of interfaces is changed, an additional variable must be taken into consideration. Also the influence of preceding $R$-phase transformation on the subsequent martensitic transformation is not considered.

Due to the different nature of the R-phase different effect of the microstructural features (dislocations, particles) on the start of the transformation have to be expected. Although the variation of equilibrium temperature $T_{0}$ (by changes in chemical compostion $c_{N i}$ ) should affect $M_{s}$ and $R_{c s}$ in the same way, the effect of stress fields on the two temperatures is different. Internal shear stresses close to precipitations are able to favour the $\mathrm{R}$-phase. The conclusion may be that an increase of internal stress $\tau_{i}$ will raise the $R_{c s}$-temperature. Depending on the annealing temperature $T_{\Lambda}$, the effects of variables on $R_{c s}$-temperature can possibly be described by:

$$
\left.\frac{d R_{c s}}{d T_{A}}\right|_{t_{A}}= \pm \frac{\delta T_{0}}{\delta c_{N i}} \frac{\delta c_{N i}}{\delta T_{A}}+\frac{\delta \Delta T_{R}}{\delta \tau_{\hat{i}}} \frac{\delta \tau_{i}}{\delta T_{A}}
$$

for constant annealing time $t_{A}$ (isochronal reaction). Partial recovery does not change the $R$-phase transition behaviour as long as the necessary internal stress exists. Only the beginning of partial recrystallization processes concomitant with dissolution (or overaging) of precipitates leads to disappearance of the R-phase transformation in cold worked Ni-rich NiTi-alloys. 
After annealing at $350{ }^{\circ} \mathrm{C}$ the $\mathrm{R}_{\mathrm{cs}}$-temperature is raised (Fig. 10). Internal shear stress close to precipitations as well as the decrease of Ni-content in the matrix are probably able to shift the R-phase to higher temperatures. The $\mathrm{M}_{s}$-temperature remains unchanged (Fig. 10). The increase of necessary undercooling caused by precipitation hardening and the raise of the $T_{0}$-temperature seems to compensate each other.

The $450{ }^{\circ} \mathrm{C}$ heat treated sample shows a slight increase of $\mathrm{R}$-phase temperature due to decreasing nickel content. Presumably the internal stress fields around the grown precipitations are able to favour the R-phase transition furthermore. The decrease of matrix hardness (Fig. 8) and the increase of equilibrium temperature should raise $\mathrm{M}_{\mathrm{s}}$. In contrast to this a slight drop can be observed (Fig. 10). It can be supposed that the probability of nucleation for martensitic transformation decreases additionally. It could not be clarified whether the subsequent martensitic transformation is influenced by the preceding R-phase transformation.

The $550{ }^{\circ} \mathrm{C}$ heat treated specimen does not show any precipitations. So the formation of R-phase by precipitation stress fields can be excluded and a decrease of equilibrium temperature (because of raising nickel content) must be supposed. The shear from the stress fields of the remaining dislocations is obviously not sufficient to keep the R-phase transformation at the former high temperature (Fig. 10). An increase in Ni-content due to dissolution of Ni-rich particles should overcompensate the increase in $\mathrm{M}_{\mathrm{s}}$-temperature from decreasing dislocation density (Fig. 10).

With the beginning recrystallization after $600{ }^{\circ} \mathrm{C}$ heat treatment, no more $\mathrm{R}$-phase transformation can be detected (Table 1, Fig. 9c). It can be presumed that the decreasing dislocation stress is not able to produce the R-phase transformation. The low necessary undercooling (due to the decreasing strength) favours the increase of the $M_{s}$-temperature (Fig. 10).

In summary all of our results can be explained by the different nature of $\mathrm{R}$ - and M-transformations. The hardening mechanisms of the austenite impede the long range first order M-transformation (Fig. 11). The same structural features remain unaffected by the R-phase and even stimulate this transformation due to its dispersed nature (Fig. 11).

\section{References}

/1/ Hornbogen E., Met. Trans. 10A (1979) 947-972

12/ Moberly W. J., Proft J. L., Duerig T. W., Sinclair R., Acta metall mater. 38 (1990) 2601-2612

/3/ Nishida M., Wayman C. M., Honma T., Met. Trans. 17A (1986) 1505-1515

/4/ Kreye H., Z. Metallkde. 62 (1971) 441-444

15/ Hornbogen E, Kobus E, Prakt. Metallogr. 30 (1993) $10507-519$

16/ Hornbogen E., Acta metall. mater. 33 (1985) 595-601

\section{Acknowledgements}

We gratefully acknowledge the support of the DFG (German Science Foundation, Ho 325/33-1) and Mercedes Benz AG (Stuttgart).

Table 1: Phase transformation temperatures $\left[{ }^{\circ} \mathrm{C}\right]$.

\begin{tabular}{|c||c|c|c|c|c|c|c|c|c|}
\hline Sample & Figure & $\mathrm{R}_{\mathrm{cs}}$ & $\mathrm{R}_{\mathrm{cf}}$ & $\begin{array}{c}\mathrm{M}_{\mathrm{s}} \\
\left(\mathrm{M}_{\mathrm{s}}^{*}\right)\end{array}$ & $\begin{array}{c}\mathrm{M}_{\mathrm{f}} \\
\left(\mathrm{M}_{\mathrm{f}}^{*}\right)\end{array}$ & $\mathrm{R}_{\mathrm{hs}}$ & $\mathrm{R}_{\mathrm{hf}}$ & $\begin{array}{c}\mathrm{A}_{\mathrm{s}} \\
\left(\mathrm{A}_{\mathrm{s}}^{*}\right)\end{array}$ & $\begin{array}{c}\mathrm{A}_{\mathrm{f}} \\
\left(\mathrm{A}_{\mathrm{f}}^{*}\right)\end{array}$ \\
\hline \hline $\mathrm{IS}$ & $9 \mathrm{a}$ & 19 & -28 & $-23^{*}$ & $-85^{*}$ & -32 & - & - & $26^{*}$ \\
\hline $350^{\circ} \mathrm{C}$ & $9 \mathrm{a}$ & 38 & -13 & $-25^{*}$ & $-90^{*}$ & 1 & - & - & $31^{*}$ \\
\hline $450^{\circ} \mathrm{C}$ & $9 \mathrm{~b}$ & 40 & 8 & $-29^{*}$ & $-80^{*}$ & 12 & 37 & $27^{*}$ & $45^{*}$ \\
\hline $550^{\circ} \mathrm{C}$ & $9 \mathrm{a}$ & 1 & -18 & $-34^{*}$ & $-63^{*}$ & -1 & - & - & $20^{*}$ \\
\hline $600^{\circ} \mathrm{C}$ & $9 \mathrm{c}$ & - & - & -6 & -46 & - & - & -4 & 2 \\
\hline
\end{tabular}




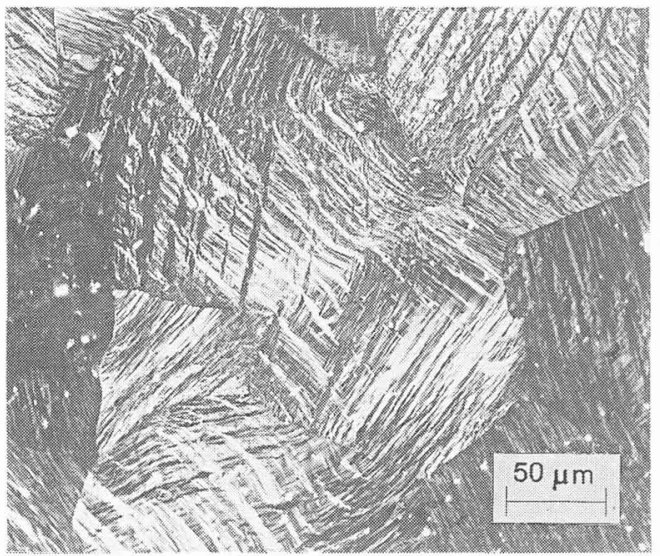

Fig. 1: Deformed austenire. By light microscopy no differences between IS and heat treated conditions up to $550{ }^{\circ} \mathrm{C}$ can be found. (LM)

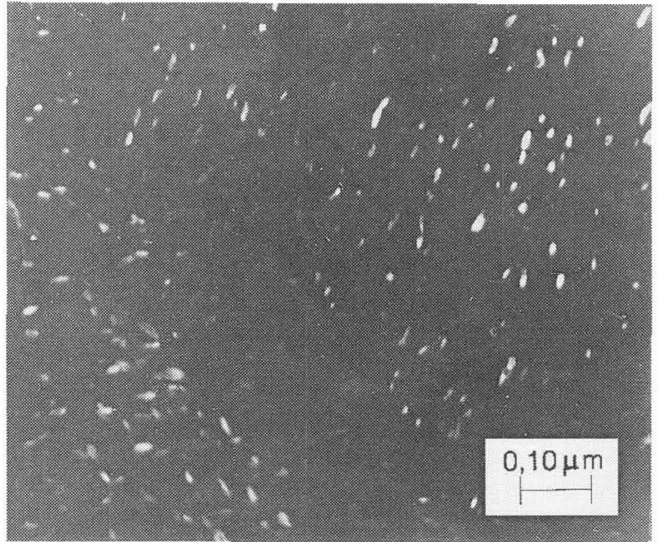

Fig. 3: Darkfield image of precipitations afier annealing at $450{ }^{\circ} \mathrm{C}$ (average diameter $40 \mathrm{~nm}$ ). (TEM)

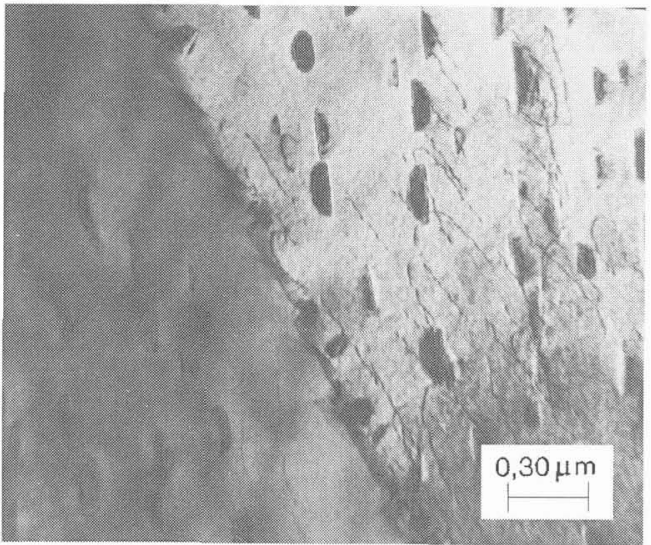

Fig. 5: In contrast to Fig. 4 , precipitaions of $200 \mathrm{~nm}$ size can be observed afler hot forming and annealing at $550^{\circ} \mathrm{C}$. (TFM)

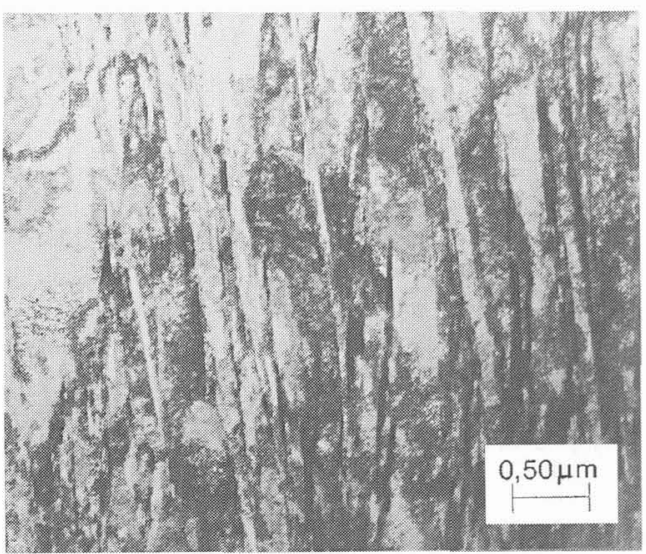

Fig. 2: No evident recovery can be found between the initial state $I S$ and $350^{\circ} \mathrm{C}$. (TEM)

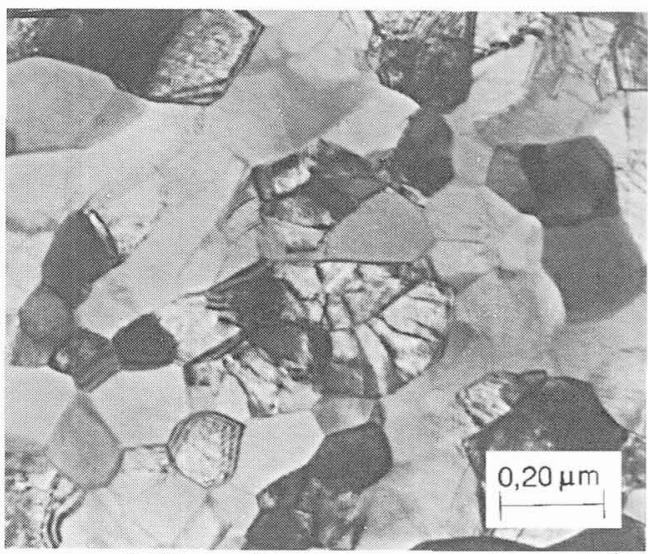

Fig. 4: Subboundary stmichure after $550^{\circ} \mathrm{C}$ heat treatment. No more precipitations can be observed. (TEM)

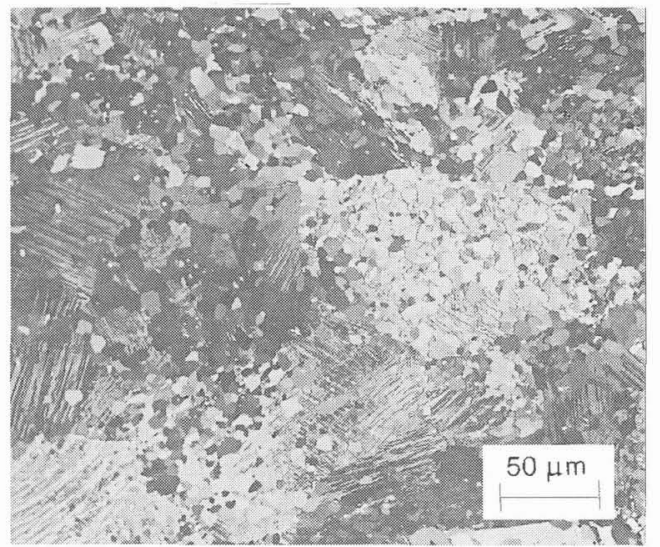

Fig. 6: Pantial recrystallization after $600{ }^{\circ} \mathrm{C}$ heat treatment. Size of the newly formed grains from 5 to $12 \mu \mathrm{m}$. (LM) 


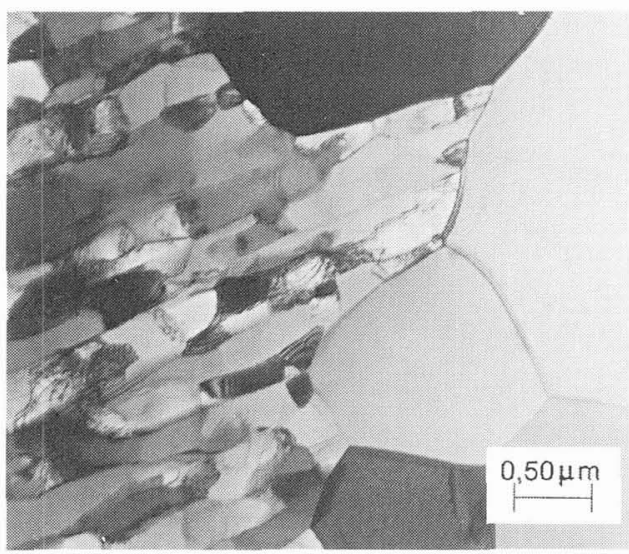

Fig. 7: Subgrains and partial recrystallization after annealing at $600^{\circ} \mathrm{C}$. No precipitations can be observed. (TEM)

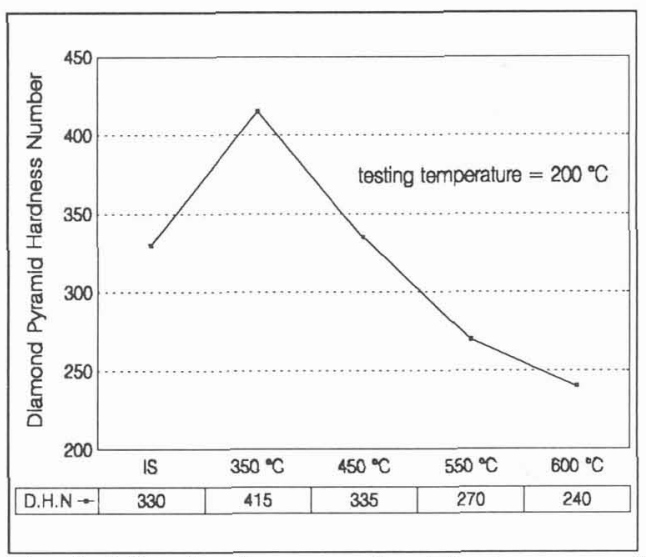

Fig. 8: Microhardness results. The increase of hardness is evident for the coherency of the particles afier annealing at $350^{\circ} \mathrm{C}$.

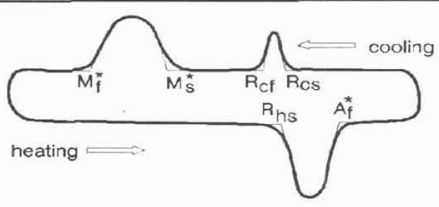

a) $1 \mathrm{~S}, 350^{\circ} \mathrm{C}, 550^{\circ} \mathrm{C}$

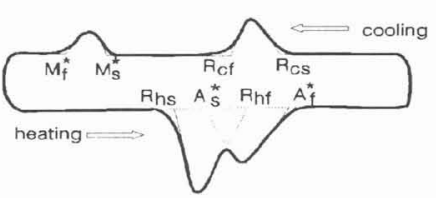

b) $450^{\circ} \mathrm{C}$

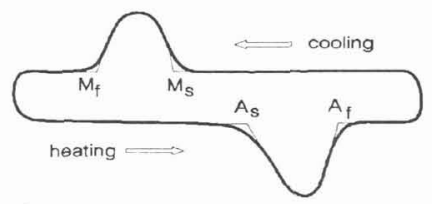

c) $600^{\circ} \mathrm{C}$

Fig. 9: Three different types of Iransformation during DSC-measurements. Temperatures which are marked by * follow an R-Phase iransformation.

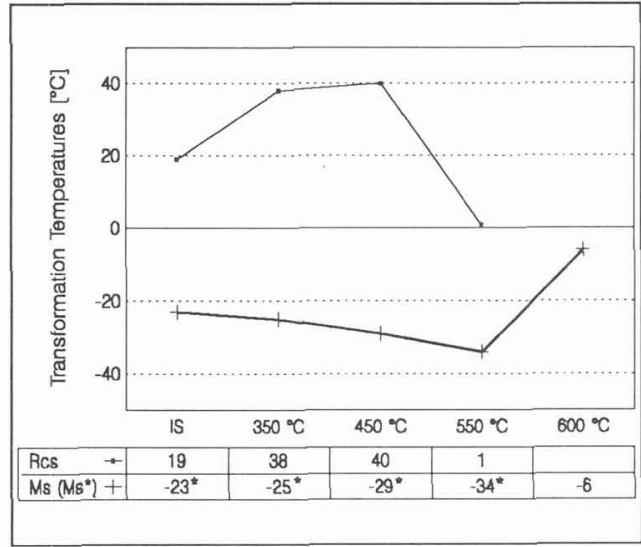

Fig. 10: Effect of heat treatment on $R_{c s}-$ and $M_{s}$-temperatures.

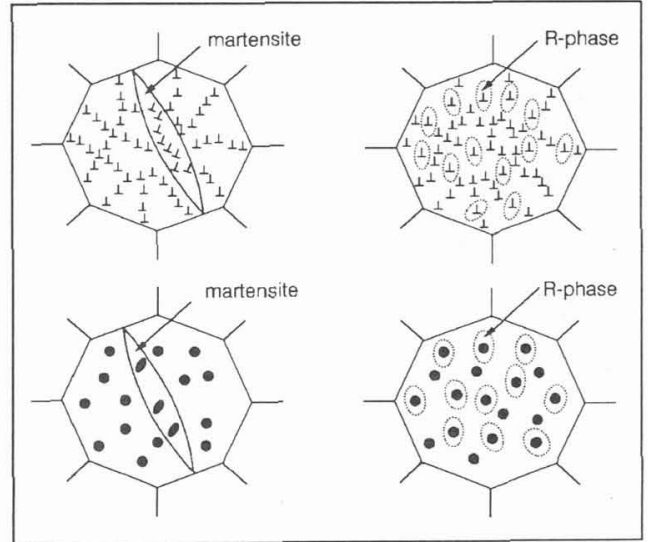

Fig. 11: Effect of hardening mechanisms on $M$ - and R-phase transformation (schematic characterization). 